\title{
Applying Tabu Search Optimisation in Zone Distribution System Reconfiguration: A Stochastic Model
}

\author{
Rana A. Abttan ${ }^{1}$ and Maad M. Mijwil ${ }^{2}$ \\ ${ }^{1}$ Computer Techniques Engineering Department, Baghdad College of Economic Sciences University \\ Baghdad, Iraq \\ Email: rana.ali.abttan [AT] baghdadcollege.edu.iq \\ ${ }^{2}$ Computer Techniques Engineering Department, Baghdad College of Economic Sciences University \\ Baghdad, Iraq \\ Email: mr.maad.alnaimiy [AT] baghdadcollege.edu.iq
}

\begin{abstract}
The main idea in the distribution system is to reconfigure the network and to change the sectionalizing switches' state to reduce power loss and maintain system stability. In network reconfiguration, a key role is to find the appropriate network topology that does have the lowest losses during any conditions present within the network. Reliability, security, and system operating limitations are the most significant parts of the network reconfiguration that are suitable. In the work, the authors suggested to apply Tabu search optimisation technique to solve the problem of network reorganisation in the distribution system by creating a stochastic model of a virtual zone based on data prepared in a previous study by the first author. The stochastic model consists of four feeders and 106 buses. The validity of the suggested technique is verified by relying on standard practices and its ability to establish a correct network topology in the system distribution. This investigation determines that the suggested technique is excellently suitable for creating a virtual zone network and can be applied in reality.
\end{abstract}

Keywords - Tabu search, Network topology, Stochastic model, Optimisation, Distribution system.

\section{INTRODUCTION}

Network reconfiguration [1] [2] can be described as shutting down and opening the switches in order to change the network topology and thus getting the energy flow from the substation to the customers. Moreover, the distribution feeders include a number of switches [3]. Some of them are characterised by being closed, they are also called sectionalising switches or the second type of switches that are distinguished as open or tie switches. When an event occurs in the network, the network is reconfigured by opening or shutting down the switches in the network under several restrictions that must be followed within the network. The imposed limitations can be summarised as follows: the operating must be in the radial configuration [4], identifying and processing loads correctly [5], the lines [6], transformers [7] and other equipment must generally operate without modifying their capacity limits, and the organisational and structural limitations of the bus voltage in the network must not vary. In 1989 there is a study by Shirmohammadi et al. from the USA [8]. They suggest adding a computational efficiency branch and bound type heuristic method of the related type to reconfigure the distribution system correctly and for the minimum loss. The researchers Borozan and Rajakovic, in their article which is printed in 1997 in IEEE Transactions on Power Delivery, present realistic short-term planning for executing network reconfiguration [9]. A study that is conducted by Lin and Chin [10] shows that in the reconfiguration technique that is mainly aimed at reducing losses, switch indicators are utilised based on the drop in branch voltage and branch constraints. In a study published by Robert et al. in 2004 [11], they propose applying a genetic algorithm for optimal network reconfiguration to minimise losses and control it through fuzzy logic. Crucially, the best solution for a sample distribution system reconfiguration is taken by selecting brute-force and ant-colony methods. Effects and system data of these methods are exhibited in [12] [13].

The main contribution of the current study is applying the Tabu-Search optimization technique to find the optimal network reconfiguration. This technique is described by meeting many requirements and adherence to operational restrictions. Its main objective is the minimum losses and also the radiality and voltage drop constraints. As for the data that is relied upon in creating the stochastic model, they are study data collected by the first author and published in her study in 2011 . 


\section{THE POWER LOSS DERIVATION}

In fact, the distribution system is mainly composed of a main radial feeder only. Figure 1 displays a single-line diagram of such a feeder that consists of $n$ branches or nodes [14].

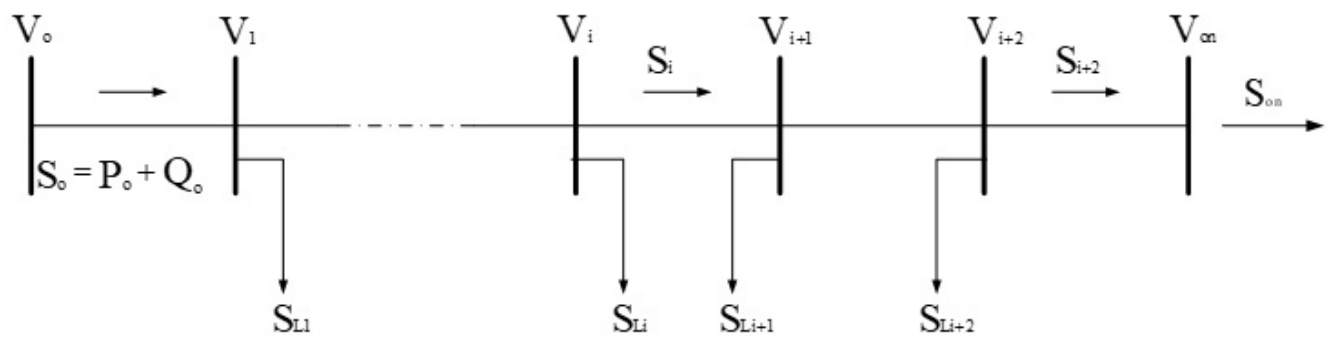

Figure 1: Single-line diagram of a main radial feeder.

In order to realize the power flow of the radial distribution network, analytical formulas $1 \mathrm{a}$, ab, and $1 \mathrm{c}$ are used, which describe the real power, reactive power, and voltage at the transmitter and receiver ends of a specific branch. Formulas (1) are designated the branch flow formulas.

$$
\begin{gathered}
P_{i+1}=P_{i}-r_{i+1} \frac{P_{i}^{2}+Q_{i}^{2}}{\left|V_{i}\right|^{2}}-P_{L i+1} \\
Q_{i+1}=Q_{i}-X_{i} \frac{P_{i}^{2}+Q_{i}^{2}}{\left|V_{i}\right|^{2}}-Q_{L i+1} \quad \text { (la) } \\
\left|V_{i+1}\right|^{2}=\left|V_{i}\right|^{2}-\left(G_{i+1} * P_{i}+X_{i+1} * Q_{i}\right)^{2}+\left(X_{i+1}^{2}+r_{i+1}^{2}\right) \frac{P_{i}^{2}+Q_{i}}{\left|V_{i}\right|^{2}}
\end{gathered}
$$

Formulas (1), are termed the branch flow equations. Description of power flow in the structure of a radial distribution network through a given set of recursive branch flow formulas (Formulas 1) Description of power flow in the structure of a radial distribution network through a given set of recursive branch flow formulas. For the terms quadratic they are represented by the formulas of losses in the branches. These terms are characterised in that their values are smaller than power terms $P_{i} \& Q_{\mathrm{i}}$, so they will be overlooked in implementation. Formulas (2) represent the new branch formulas as follows:

$$
\begin{gathered}
P_{i+1}=P_{i}-P_{L i+1} \\
Q_{i+1}=Q_{i}-Q_{L i+1} \\
\left|V_{i+1}\right|^{2}=\left|V_{i}\right|^{2}-\left(G_{i+1}^{v} * P_{i}+X_{i+1} * Q_{i}\right)^{2}
\end{gathered}
$$

The power loss $\left(P L_{i \mathfrak{i}}\right)$ in a branch is computed as given by formula 3. The total system loss $T S_{i}$ is the total of all branches loss performed by formula (4).

$$
\begin{gathered}
P L_{i}=x_{i}\left[\frac{P_{i}^{2}+Q_{i}^{2}}{V_{i}^{2}}\right] \\
T S_{i}=\sum_{i}^{n} n_{i}^{n}\left[\frac{P_{i}^{2}+Q_{i}^{2}}{V_{i}^{2}}\right]
\end{gathered}
$$

\section{THE OPTIMISATION PROBLEM}

In this section, the problem of the distribution system reconfiguration is discussed mathematically as shown below [15]. The primary purpose of reconfiguring the feeding unit is to reduce the distribution of losses of system created in the stochastic model by utilising on/ off the partition switches.

Subject to:

$$
\operatorname{Min} . \text { Cost }=\sum_{i=1}^{L} x_{i} \frac{\left(P_{i}^{2}+Q_{i}^{2}\right)}{V_{i}^{2}}
$$

$$
g(x)=0
$$




$$
\begin{gathered}
V_{i}^{\min }<V_{i}<V_{i}^{\max } \\
I_{i}^{\min }<I_{i}<I_{i}^{\max } \\
\text { Radial system } \rightarrow \operatorname{det}(A)=1 \text { or }-1 \\
\text { Not Radial system } \rightarrow \operatorname{det}(A)=0
\end{gathered}
$$

Two subgroups are configured through which to verify the constraints of the network reconfiguring, as follows [16]: Subgroup-1 reviewing for the supply provision and radiality of the system. This job is prepared before the load flow. Subgroup-2 is reviewing for voltage drop and line capacity limits. This job is prepared after the load flow. The following points explain the constraints that are imposed on network reconfiguring:

- Point\#1 is radial network constraint: the distribution network shall hold a radial structure, taking into account the operational point of view. Consequently, each section has included one up-stream section.

- Point\#2 is power source limit constraint: It is designated that the total loads for each sub-network do not exceed the capacity limit of the corresponding power source significantly.

- Point\#3 is voltage constraint: voltage magnitude at each level of a section shall happen within their acceptable ranges.

- Point\#4 is current constraint: the current magnitude of each branch (line and switch) shall happen within their acceptable ranges.

\section{TABU SEARCH ALGORITHM}

In 1986 American computer researcher Fred W. Glover states the Tabu Search (TS) algorithm [17] [18] allows local search techniques to overcome local optima. This algorithm is publicly and widely employed to solve combinatorial optimisation problems that classic optimisation methods have a significant challenge in solving within practical and effective time limits. This algorithm is characterised by using some sensible ideas to enable the search process to disappear from the local optimum level. This yields solutions and predictions that often exceed their quality and are characterised by the speed of completion of tasks, and this is why, it has been utilised in this work. The principal factors of the TS algorithm are [19-21]:

- Solution representation: Each likely solution to the optimisation obstacle must have a unique representation within the search space.

- Cost function: This function is drafting each available solution into a value representing its optimization cost. The algorithm aims to discover a solution that reduces this value.

- Neighbourhood: A function mapping each feasible solution $S$ into a set of other solutions. Each time the algorithm has to judge a new key, it is taken from the modern solution's neighbourhood.

- Tabu list: A list including the last $T$ moves carried out, which for this reason are blocked. A solution received from the modern solution S with an action included in the Tabu list cannot (in general) be a part of S's neighbourhood.

- Aspiration criterion: If a Tabu move (a move which is included in the Tabu list) satisfies this rule, then the solution achieved by utilising it to the modern solution $S$ can be judged to be in the neighbourhood of $S$. The usual measure is that the move gives the best solution received so far. where $S$ is search space.

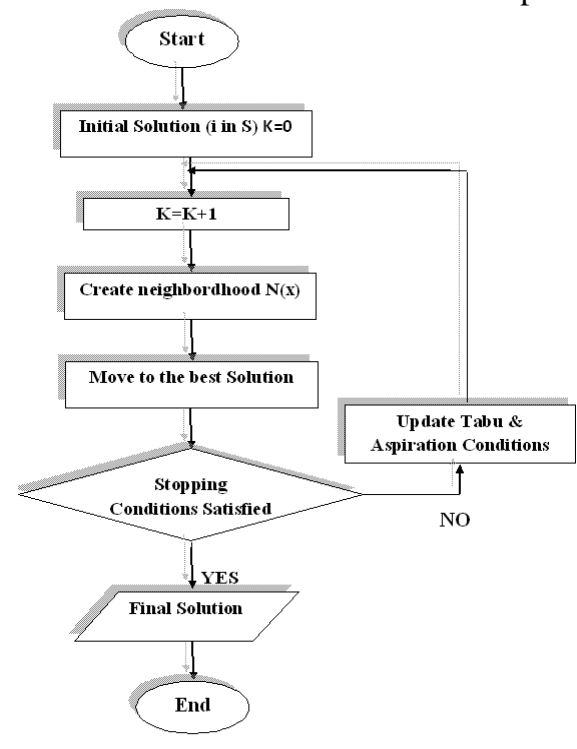

Figure 2: Flow chart of Standard 
Figure 2 presents a flowchart of the TS algorithm. This scheme is defined as follows:

Round 1: Enter all distribution system data and all operational constraints, and this step includes configuring the fundamental parameters in the distribution system (maximum iteration and iteration index $\mathrm{K}=0$ ). After that, the current situation is configured $R$ and $R \in S$. The optimal solution is $R_{\text {optimal }}=R$. The modern solution is designed by the switch number that should be started during network reconfiguration.

Round 2: Establish the value of $K=K_{1}+1$. This round is essential in making the system data.

Round 3: Implement a load flow program in each configuration in the Tabu list. Preservation of the radial configuration of the system is given in the Tabu list after properly verifying the algorithm of the beam for calculating the power loss, where the structure is determined with minimal power loss, and the bus voltage is measured in the system.

Round 4: Through this round, the aspiration level is calculated, as the total power losses in the system are known through formula (11). A batch of solutions is produced from the neighbourhood of $R$ by changing the switch numbers that must be unlocked. This batch of solutions is indicated of $R_{\text {neighbourhood }}$

$$
R_{\text {optimal }} j_{\text {optimal }}=f\left(R_{\text {optînal }}\right)
$$

Round 5: This round has two possibilities, either setting the current power loss to equal the new power loss or making settings to restore the previous configuration and undo this round.

Round 6: If a stopping circumstance is matched, then it stops. Else go to round 2.

Round 7: Finish/Stop.

\section{ALGORITHM VALIDATION}

The TS algorithm is first used to find the optimal feeder configuration of well documented systems. Three standard systems are considered [22- 24]. Table 1 shows the here used TS algorithm results along with those obtained in the respective references. The results of Table 1 verify the validity of the TS algorithm adopted in this work.

Table 1: (16-18-32)-bus system results using TS algorithm in comparison with other techniques [25].

\begin{tabular}{|c|c|c|}
\hline System & Losses & Tie switches \\
\hline 16- bus system & $\begin{array}{l}\text { Before reconfiguration }=511.435 \mathrm{~kW} \\
\text { After reconfiguration using (SA) }[22]=466.1 \mathrm{~kW} \\
\text { After reconfiguration using proposed TS }=466.1 \mathrm{~kW}\end{array}$ & $\begin{array}{l}{[(5-11),(10-14),(7-16)]} \\
\text { Before }[(8-10),(9-11) \\
\quad(7-16)] \text { After }\end{array}$ \\
\hline 18-bus system & $\begin{array}{l}\text { Before reconfiguration }=112.34 \mathrm{~kW} \\
\text { After reconfiguration using }(\mathrm{GA})[23]=107.48 \mathrm{~kW} \\
\text { After reconfiguration using proposed TS }=103.7 \mathrm{~kW}\end{array}$ & $\begin{array}{c}{[(6-10),(13-17)] \text { Before }} \\
{[(6-10),(16-17)] \text { After }}\end{array}$ \\
\hline 32- bus system & $\begin{array}{l}\text { Before reconfiguration=202.6 kW } \\
\text { After reconfiguration using Artificial Bee Colony Algorithm [24] = } \\
139.5 \mathrm{~kW} \text { After reconfiguration using proposed TS=139.5 kW }\end{array}$ & $\begin{array}{l}{[(8-21),(9-15),(12-22),(18-} \\
33),(25-29)] \text { Before } \\
{[(7-8),(14-15),(9-10),(32-} \\
33),(25-29)] \text { After }\end{array}$ \\
\hline
\end{tabular}

\section{DATASETS AND EVALUATIONS}

The design of the stochastic model is based on data from an Iraqi company organised by the first author in [25]. The stochastic model consists of three feeder station transformers of 132/33/11 kV with a power rating of 63/50/25 MVA. Six feeders at the $33 \mathrm{kV}$ level feed six $33 / 11 \mathrm{kV}$ substations. Fifteen $11 \mathrm{kV}$ feeders outgoing from this stochastic station serve many mixed residential, manufacturing, and trading loads. In this work, only four of one of the three transformer substations are needed. Also, this model is rated at $11 \mathrm{kV}$ with 101 sectionalizing switches, 102 buses, and 4 tie switches. The system data is provided in Table 2. Moreover, the model's actual and reactive load requirements are utilised for each bus without any content change. The total loads are $17,531 \mathrm{~kW}$ with a substantial initial model power loss of $200.82 \mathrm{~kW}$. When we apply the suggested TS algorithm to the stochastic model, the last power loss is $155.2 \mathrm{~kW}$. The effects of Table 3 confirm that the power loss after reconfiguration is $22.7 \%$ less than its initial value. Besides, Figure 3 (a) displays the voltage profile before and after the feeder reconfiguring. As recorded, most of the bus voltages are updated after feeder reconfiguring. The smallest bus voltage is 0.9769 p.u. And after reconfiguration, it is raised to 0.9818 p.u. Figure 3 (b) proves the presence of the best Tabu transactions recorded during the search process, which will give us effects that lead to reducing the cost function. Also, there are only six movements that lead to the ideal solution. Four ties are elected to be closed at each round, and an equivalent number of splitter switches open if this reduces the power loss in this model. The duration of the implementation of the grown program is about 25 minutes. Table 4 displays the statistics of the cost function in the simulation effects. 
Table 2: Stochastic feeder model: line and bus data

\begin{tabular}{|c|c|c|c|c|c|c|}
\hline \multirow[b]{2}{*}{$\begin{array}{l}\text { Line } \\
\text { No. }\end{array}$} & \multirow[b]{2}{*}{$\begin{array}{l}\text { From } \\
\text { Bus }\end{array}$} & \multirow[b]{2}{*}{$\begin{array}{c}\text { To } \\
\text { Bus }\end{array}$} & \multirow[b]{2}{*}{$\mathrm{R}(\Omega)$} & \multirow[b]{2}{*}{$\mathrm{X}(\Omega)$} & \multicolumn{2}{|c|}{ End Bus } \\
\hline & & & & & $\begin{array}{c}\text { Real Power } \\
\text { Load }(k W)\end{array}$ & $\begin{array}{c}\text { Reactive } \\
\text { Power Load } \\
\text { (kVAr) }\end{array}$ \\
\hline 1. & 0 & 1 & 0 & 0 & 0 & 0 \\
\hline 2. & 1 & 2 & 0.1749 & 0.1289 & 0 & 0 \\
\hline 3. & 2 & 3 & 0.0885 & 0.0971 & 200 & 150 \\
\hline 4. & 3 & 4 & 0.1026 & 0.1126 & 340 & 210 \\
\hline 5. & 4 & 5 & 0.0490 & 0.0538 & 200 & 150 \\
\hline 6. & 5 & 6 & 0.0106 & 0.0182 & 0 & 0 \\
\hline 7. & 6 & 7 & 0.1013 & 0.1111 & 200 & 150 \\
\hline 8. & 7 & 8 & 0.0350 & 0.0383 & 340 & 210 \\
\hline 9. & 8 & 9 & 0.0576 & 0.0632 & 200 & 150 \\
\hline 10. & 9 & 10 & 0.0618 & 0.0678 & 200 & 150 \\
\hline 11. & 3 & 11 & 0.0160 & 0.0176 & 0 & 0 \\
\hline 12. & 11 & 12 & 0.0093 & 0.0102 & 340 & 210 \\
\hline 13. & 11 & 13 & 0.1215 & 0.1333 & 340 & 210 \\
\hline 14. & 5 & 14 & 0.0408 & 0.0448 & 0 & 0 \\
\hline 15. & 14 & 15 & 0.0087 & 0.0095 & 200 & 150 \\
\hline 16. & 14 & 16 & 0.0305 & 0.0334 & 200 & 150 \\
\hline 17. & 8 & 17 & 0.0368 & 0.0403 & 340 & 210.71 \\
\hline 18. & 1 & 18 & 0.0218 & 0.0160 & 0 & 0 \\
\hline 19. & 18 & 19 & 0.0583 & 0.0639 & 200 & 150 \\
\hline 20. & 19 & 20 & 0.0359 & 0.0393 & 0 & 0 \\
\hline 21. & 20 & 21 & 0.0229 & 0.0252 & 0 & 0 \\
\hline 22. & 21 & 22 & 0.0970 & 0.1064 & 0 & 0 \\
\hline 23. & 22 & 23 & 0.0330 & 0.0362 & 0 & 0 \\
\hline 24. & 23 & 24 & 0.0085 & 0.0093 & 200 & 150 \\
\hline 25. & 24 & 25 & 0.0197 & 0.0217 & 200 & 150 \\
\hline 26. & 25 & 26 & 0.0437 & 0.0479 & 200 & 150 \\
\hline 27. & 18 & 27 & 0.0167 & 0.0181 & 0 & 0 \\
\hline 28. & 27 & 28 & 0.0224 & 0.0245 & 0 & 0 \\
\hline 29. & 28 & 29 & 0.0054 & 0.0138 & 200 & 150 \\
\hline 30. & 19 & 30 & 0.0195 & 0.0214 & 200 & 150 \\
\hline 31. & 20 & 31 & 0.0202 & 0.0222 & 340 & 210.71 \\
\hline 32. & 22 & 32 & 0.0102 & 0.0112 & 200 & 150 \\
\hline 33. & 32 & 33 & 0.0076 & 0.0083 & 200 & 150 \\
\hline 34. & 32 & 34 & 0.0034 & 0.0037 & 200 & 150 \\
\hline 35. & 23 & 35 & 0.0169 & 0.0185 & 200 & 150 \\
\hline 36. & 35 & 36 & 0.0216 & 0.0237 & 200 & 150 \\
\hline 37. & 24 & 37 & 0.0309 & 0.0334 & 200 & 150 \\
\hline 38. & 37 & 38 & 0.0298 & 0.0327 & 200 & 150 \\
\hline 39. & 25 & 39 & 0.0332 & 0.0364 & 200 & 150 \\
\hline 40. & 27 & 40 & 0.0465 & 0.0510 & 200 & 150 \\
\hline 41. & 28 & 41 & 0.0538 & 0.0138 & 200 & 150 \\
\hline 42. & 41 & 42 & 0.0193 & 0.0212 & 200 & 150 \\
\hline 43. & 29 & 43 & 0.0282 & 0.0309 & 200 & 150 \\
\hline 44. & 1 & 44 & 0.0461 & 0.0340 & 0 & 0 \\
\hline 45. & 44 & 45 & 0.0081 & 0.0022 & 0 & 0 \\
\hline 46. & 45 & 46 & 0.0141 & 0.0155 & 200 & 150 \\
\hline 47. & 45 & 47 & 0.0151 & 0.0165 & 0 & 0 \\
\hline 48. & 47 & 48 & 0.0707 & 0.0776 & 200 & 150 \\
\hline 49. & 48 & 49 & 0.0311 & 0.0341 & 200 & 150 \\
\hline 50. & 49 & 50 & 0.0305 & 0.0334 & 200 & 150 \\
\hline 51. & 50 & 51 & 0.0516 & 0.0566 & 200 & 150 \\
\hline 52. & 51 & 52 & 0.0245 & 0.0269 & 200 & 150 \\
\hline 53. & 52 & 53 & 0.0116 & 0.0127 & 200 & 150 \\
\hline 54. & 47 & 54 & 0.0970 & 0.1066 & 200 & 150 \\
\hline 55. & 54 & 55 & 0.0305 & 0.0334 & 0 & 0 \\
\hline 56. & 54 & 56 & 0.0066 & 0.0072 & 0 & 0 \\
\hline 57. & 48 & 57 & 0.0151 & 0.0165 & 200 & 150 \\
\hline
\end{tabular}




\begin{tabular}{|c|c|c|c|c|c|c|}
\hline 58. & 50 & 58 & 0.0386 & 0.0424 & 200 & 150 \\
\hline 59. & 51 & 59 & 0.0308 & 0.0338 & 340 & 210.71 \\
\hline 60. & 59 & 60 & 0.0141 & 0.0155 & 200 & 150 \\
\hline 61. & 53 & 61 & 0.0298 & 0.0327 & 340 & 210.71 \\
\hline 62. & 53 & 62 & 0.0116 & 0.0127 & 200 & 150 \\
\hline 63. & 62 & 63 & 0.0119 & 0.0210 & 200 & 150 \\
\hline 64. & 63 & 64 & 0.0160 & 0.0176 & 200 & 150 \\
\hline 65. & 55 & 65 & 0.0267 & 0.0293 & 200 & 150 \\
\hline 66. & 55 & 66 & 0.0173 & 0.0189 & 200 & 150 \\
\hline 67. & 66 & 67 & 0.0210 & 0.0231 & 200 & 150 \\
\hline 68. & 1 & 68 & 0.0265 & 0.0195 & 0 & 0 \\
\hline 69. & 68 & 69 & 0.0028 & 0.0031 & 0 & 0 \\
\hline 70. & 69 & 70 & 0.0235 & 0.0258 & 340 & 210.71 \\
\hline 71. & 69 & 71 & 0.0500 & 0.0548 & 200 & 150 \\
\hline 72. & 71 & 72 & 0.0248 & 0.0272 & 200 & 150 \\
\hline 73. & 72 & 73 & 0.0361 & 0.0396 & 200 & 150 \\
\hline 74. & 73 & 74 & 0.0232 & 0.0255 & 0 & 0 \\
\hline 75. & 74 & 75 & 0.0456 & 0.0500 & 80 & 60 \\
\hline 76. & 75 & 76 & 0.0173 & 0.0189 & 0 & 0 \\
\hline 77. & 76 & 77 & 0.0099 & 0.0108 & 340 & 210.71 \\
\hline 78. & 77 & 78 & 0.0082 & 0.0089 & 0 & 0 \\
\hline 79. & 78 & 79 & 0.0113 & 0.0124 & 0 & 0 \\
\hline 80. & 74 & 80 & 0.0308 & 0.0338 & 0 & 0 \\
\hline 81. & 80 & 81 & 0.0447 & 0.0490 & 900 & 435.89 \\
\hline 82. & 81 & 82 & 0.0161 & 0.0177 & 0 & 0 \\
\hline 83. & 82 & 83 & 0.0327 & 0.0358 & 200 & 150 \\
\hline 84. & 83 & 84 & 0.0284 & 0.0312 & 200 & 150 \\
\hline 85. & 84 & 85 & 0.0225 & 0.0280 & 200 & 150 \\
\hline 86. & 85 & 86 & 0.0407 & 0.0447 & 200 & 150 \\
\hline 87. & 86 & 87 & 0.0051 & 0.0056 & 0 & 0 \\
\hline 88. & 87 & 88 & 0.0166 & 0.0180 & 0 & 0 \\
\hline 89. & 80 & 89 & 0.0198 & 0.0217 & 200 & 150 \\
\hline 90. & 89 & 90 & 0.0399 & 0.0438 & 200 & 150 \\
\hline 91. & 90 & 91 & 0.0214 & 0.0235 & 200 & 150 \\
\hline 92. & 82 & 92 & 0.0173 & 0.0189 & 200 & 150 \\
\hline 93. & 92 & 93 & 0.0327 & 0.0358 & 200 & 150 \\
\hline 94. & 93 & 94 & 0.0404 & 0.0443 & 200 & 150 \\
\hline 95. & 84 & 95 & 0.0385 & 0.0423 & 200 & 150 \\
\hline 96. & 87 & 96 & 0.0369 & 0.0404 & 200 & 150 \\
\hline 97. & 76 & 97 & 0.0170 & 0.0187 & 340 & 210.71 \\
\hline 98. & 78 & 98 & 0.0103 & 0.0113 & 0 & 0 \\
\hline 99. & 98 & 99 & 0.0103 & 0.0113 & 535.50 & 331.87 \\
\hline 100. & 98 & 100 & 0.0075 & 0.0082 & 0 & 0 \\
\hline 101. & 100 & 101 & 0.0103 & 0.0113 & 535.50 & 331.87 \\
\hline 102. & 100 & 102 & 0.0246 & 0.0270 & 340 & 210.71 \\
\hline $103^{*}$ & 6 & 21 & 0.0122 & 0.0134 & & \\
\hline 104* & 26 & 29 & 0.0103 & 0.0113 & & \\
\hline $105^{*}$ & 54 & 64. & 0.0170 & 0.0187 & & \\
\hline $106^{*}$ & 55 & 88 & 0.0339 & 0.0180 & & \\
\hline
\end{tabular}

Reminder: * is Tie lines

Table 3: Stochastic feeder model results using TS algorithm

\begin{tabular}{ccccc}
\hline Model & $\begin{array}{c}\text { Power } \\
\text { Loss }\end{array}$ & \%power loss & Voltage Profile (p. u.) & Tie Switches \\
\hline Before reconfiguration & $189.82 \mathrm{~kW}$ & $1.125 \%$ & $\begin{array}{c}\mathrm{V}_{\max }=1 \\
\mathrm{~V}_{\min }=0.9696\end{array}$ & $\begin{array}{c}\text { 6-21, 26-29, 54- } \\
64,55-88\end{array}$ \\
\hline After reconfiguration & $145.2 \mathrm{~kW}$ & $0.875 \%$ & $\begin{array}{c}\mathrm{V}_{\max }=1 \\
\mathrm{~V}_{\min }=0.9718\end{array}$ & $\begin{array}{c}5-6,21-22,52-53, \\
82-38\end{array}$ \\
\hline
\end{tabular}




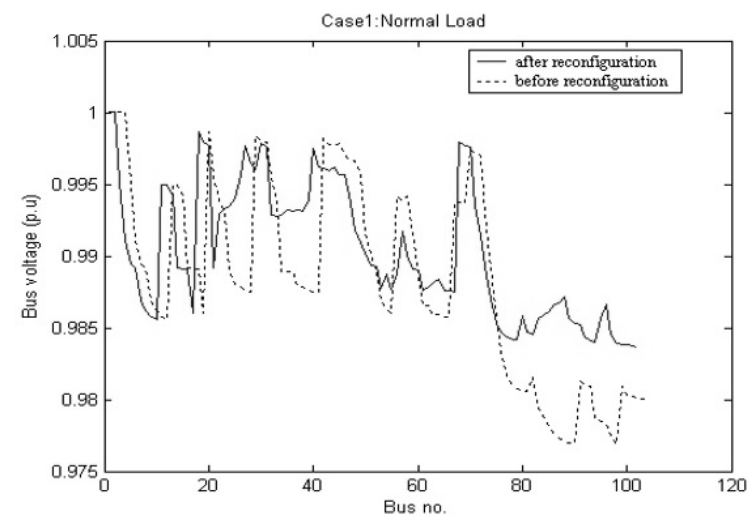

(a)

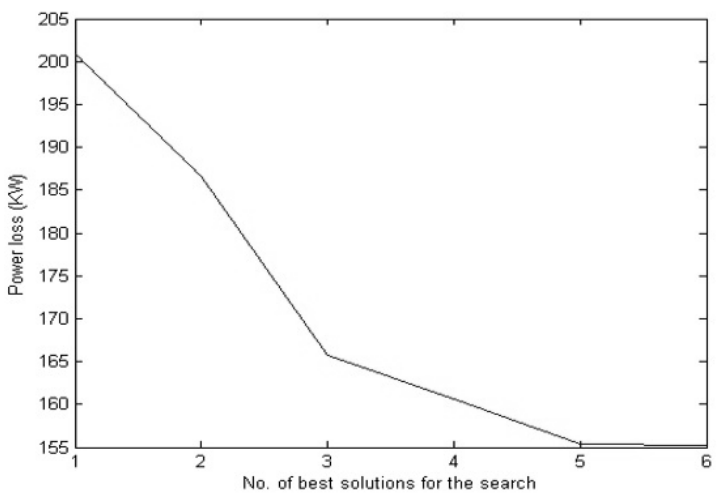

(b)

Figure 3: (a) Voltage profile for the stochastic feeder model, (b) The best moves recorded in the Tabu list during the search process for the stochastic feeder model.

\section{CONCLUSIONS}

In this paper, a standard Tabu research method is performed to solve the problem of optimal distribution network reconfiguring. It is essentially used to reduce the power loss of the model. The components of the proposed Tabu Search based method, including neighbourhood design, evaluation function design, Tabu list etc., are explained. This work is performed using a computer with the following specifications: RAM :8 GB, CPU: Intel- Core ${ }^{\mathrm{TM}}$ i7-9300 (2.40 GHz, 8M cache), programming language: MATLAB 2018a, OS: Ubuntu v.20 LTS. The proposed algorithm has been tested on standard systems. Conclusions show that the suggested Tabu Search based method is feasible, efficient and promising for distribution system reconfiguration. Extensive series of simulation studies of stochastic feeder model are performed considering different loading conditions as far as magnitude and power factor are concerned. The overall system reconfiguration pattern is almost as that of Table 3. In all the cases, the four tie switches are closed, and different sections switch to open the network topology for other loading types and issues. The general conclusion for the stochastic feeder model is better to keep the tie switches closed all the time and open the switches shown in Table 3 for all loading conditions. Table 4 displays the statistics of the cost function in the simulation effects.

\section{REFERENCES}

[1] The T. T., Ngoc D. V., and Anh N. T., "Distribution Network Reconfiguration for Power Loss Reduction and Voltage Profile Improvement Using Chaotic Stochastic Fractal Search Algorithm," Complexity-Hindawi, Vol. 2020, Article ID 2353901, pp:1-15, March 2020. https://doi.org/10.1155/2020/2353901

[2] Rajaram R., Kumar K. S., and Rajasekar N., "Power system reconfiguration in a radial distribution network for reducing losses and to improve voltage profile using modified plant growth simulation algorithm with Distributed Generation (DG)," Energy Reports, Vol.1, pp:116-122, November 2015. https://doi.org/10.1016/j.egyr.2015.03.002

[3] Gholami M., Moshtagh J., and Ghadernejad N., "Service restoration in distribution networks using combination of two heuristic methods considering load shedding," Journal of Modern Power Systems and Clean Energy, vol. 3, pp:556-564, July 2015. https://doi.org/10.1007/s40565-015-0139-6

[4] Ritter D., Franco J. F., and Romero R., "Analysis of the radial operation of distribution systems considering operation with minimal losses, International Journal of Electrical Power \& Energy Systems," vol. 67, pp:453-461, May 2015. https://doi.org/10.1016/j.ijepes.2014.12.018

[5] Zhu S. Z., Dong Z. Y., Wong K. P., and Wang Z. H., "Power System Dynamic Load Identification and Stability," In Proceedings of International Conference on Power System Technology (PowerCon 2000), pp:1-6, Perth, Australia, 4-7 December 2000. https://doi.org/10.1109/ICPST.2000.900024

[6] Mohamed S. E. G., Jasni J., Radzi M. A. M., and Hizam H., "Power System Transmission Line Overload Alleviation Using SEN Transformer," In Proceedings of International Workshops on Innovations in Energy, Power and Electrical Machines (IEPEM-2013), pp:1-6, 5-7 September, 2013, Istanbul- Turkey.

[7] Siderakis K., Pylarinos D., and Thalassinakis E., "Power transformers management in the power system of Crete," In Proceedings of International Conference on Deregulated Electricity Market Issues in South Eastern Europe, pp;1-7, 25-26 September, 2014, Nicosia, Cyprus.

[8] Shirmohammadi D. and Hong H. W., "Reconfiguration of Electric Distribution Networks for Resistive Line Losses Reduction," IEEE Transactions on Power Delivery, vol.4, no.2, pp: 1492 - 1498, April 1989. https://doi.org/10.1109/61.25637 
[9] Borozan V. and Rajakovic N., “Application Assessments of Distribution Network Minimum Loss Reconfiguration, IEEE Transactions on Power Delivery, vol. 12, no. 4, pp:1786 - 1792, October 1997. https://doi.org/10.1109/61.634206

[10] Lin W. and Chin H., "A New approach for Distribution Feeder Reconfiguration for Loss Reduction and Service Restoration," IEEE Transactions on Power Delivery, vol.13, no.3, pp:870 - 875, July 1998. https://doi.org/10.1109/61.686986

[11] Ah King R. T. F., Radha B., and Rughooputh H. C. S., "A Fuzzy Logic Controlled Genetic Algorithm for Optimal Electrical Distribution Network Reconfiguration," In Proceedings of IEEE International Conference on Networking, Sensing and Control, pp:1-6, 21-23 March 2004, Taipei, Taiwan. https://doi.org/10.1109/ICNSC.2004.1297503

[12] Morton A. B. and Mareels I. M. Y., "An Efficient Brute-Force Solution to the Network Reconfiguration Problem," IEEE Transactions on Power Delivery, vol.15, no.3, pp:996 - 1000, July 2000. https://doi.org/10.1109/61.871365

[13] Su C., Chang C., and Chiou J., "Distribution Network Reconfiguration for Loss Reduction by Ant Colony Search Algorithm," Electric Power Systems Research," vol. 75, no. 2-3, pp: 190-199, August 2005, https://doi.org/10.1016/j.epsr.2005.03.002

[14] karthikeyan S. P., Raglend J., Pratyusha P., and Kothari D. P., "A New Methodology for Distribution System Feeder Reconfiguration", International Journal of Energy, vol. 2, no.1, 2008.

[15] Mekhamer S. F., Abdelaziz A. Y., Mohammed F. M., and Badr M. A. L., "A New Intelligent Optimization Technique for Distribution Systems Reconfiguration, In Proceedings of International Middle-East Power System Conference, pp:1-6, 12-15 March 2008, Aswan, Egypt. https://doi.org/10.1109/MEPCON.2008.4562296

[16] Fukuyama Y., Fuji "Electric Corporate R \& D , LtdReactive Tabu Search. for Distribution Load Transfer Operation", IEEE INDICON, January 2000.

[17] Mijwel M. M., Tabu Search, January 2018, Retrieved from Researchgate website: https://www.researchgate.net/publication/323428615_Tabu_Search

[18]Xia Y., Fu Z., Pan L., and Duan F., "Tabu Search Algorithm for the Distance-Constrained Vehicle Routing Problem with Split Deliveries by Order," Plos One, vol.13, no.5, e0195457, pp:1-19, May 2018. https://doi.org/10.1371/journal.pone.0195457

[19] Montemanni R., Moon J. N. J., and Smith D. H., "An improved tabu search algorithm for the fixed-spectrum frequency-assignment problem," IEEE Transactions on Vehicular Technology, vol.52, no.4, pp:891 - 901, July 2003. https://doi.org/10.1109/TVT.2003.810976

[20] Romero-Conrado A. R., Coronado-Hernandez J. R., Rius-Sorolla G., and García-Sabater J. P., "A Tabu List-Based Algorithm for Capacitated Multilevel Lot-Sizing with Alternate Bills of Materials and Co-Production Environments," Applied Sciences, vol.9, pp:1-17, April 2019. https://doi.org/10.3390/app9071464.

[21] Hooshmand S., Behshameh M., and OmidHamidi, "A Tabu Search Algorithm with Efficient Diversification Strategy for High School Timetabling Problem," International Journal of Computer Science \& Information Technology, vol.5, no.4, pp:21-34, August 2013. https://doi.org/10.5121/ijcsit.2013.5402

[22] Jeon Y. and Kim J., "Application of Simulated Annealing and Tabu Search for Loss Minimization in Distribution Systems," International Journal of Electrical Power \& Energy Systems, vol.26, no. 1, pp: 9-18, January 2004. https://doi.org/10.1016/S0142-0615(03)00066-8.

[23] Taleski R. and Rajicic D., "Distribution Network Reconfiguration for Energy Loss Reduction," IEEE Transactions on Power Systems, vol.12, no.1, pp:398 - 406, February 1997. https://doi.org/10.1109/59.575733

[24] Rao R. S., Narasimham S. V. L., and Ramalingaraju M.," Optimization of Distribution Network Configuration for Loss Reduction Using Artificial Bee Colony Algorithm," International Journal of Electrical and Computer Engineering, vol.2, no.9, pp:1964-1970, 2008.

[25] Alias Q. M. and Abttan R. A., "Al - Kalij Sub-Station: Feeder Reconfiguration by Particle Swarm Optimization," Engineering and Technology Journal, vol.29, no.12., pp: 2375-2385, 2011. 